\title{
PREVALENCE OF THE OCCUPATIONAL HAZARDS AMONG MINISTRY OF HEALTH DENTISTS, ALEXANDRIA, EGYPT
}

\author{
Sherihan I. Yehia ${ }^{1} B D S$, Mona K. El Kashlan ${ }^{2} P h D$, Wafaa E. El-Din ${ }^{3} P h D$
}

\begin{abstract}
INTRODUCTION: Dentists are exposed to various hazards due to their occupation. Identifying the most prevalent ones is required to develop preventive measures and coping strategies in order to reduce the effect of such hazards in the future.

OBJECTIVES: to assess the prevalence of the different occupational hazards among the Ministry Of Health dentists, in Alexandria.

MATERIALS AND METHODS: A sample of 900 dentists working in the different Ministry of Health facilities was randomly selected from the eight health districts of Alexandria governorate. A final sample of 750 dentists participated in the study with response rate of $83.33 \%$. They were asked to complete a structured questionnaire, specially designed for the study, in order to assess their exposure to the different occupational hazards.

RESULTS: Most of participants suffered from stress (85.9\%), followed by musculoskeletal disorders (85.6\%) and 63.9\% experienced a type of percutaneous injury. Furthermore $51.3 \%$ were exposed to radiation hazards, $44.4 \%$ and $42.66 \%$ were exposed to eye injuries and chemical hazards, respectively. The least prevalent hazard was hearing impairment where it was reported by only $8.8 \%$ of the study participants CONCLUSIONS: Rheumatoid arthritis is an important risk factor for alveolar bone loss. The treatment of the RA induced rats with fish oil not only prevented the alveolar bone resorption and stimulated new bone formation, but also reduced relatively the level of rheumatoid factor in the blood.
\end{abstract}

KEYWORDS: Prevalence, occupational hazards, dentistry, Ministry of Health, Egypt.

1. B.D.S. Faculty of Dentistry Alexandria University.

2. Professor of Dental Public Health, Department of Pediatric Dentistry and Dental Public Health, Faculty of Dentistry, Alexandria University, Egypt.

3. Professor of Dental Public Health, Department of Pediatric Dentistry and Dental Public Health, Faculty of Dentistry, Alexandria University, Egypt.

\section{Corresponding author}

Name: Sherihan Ibrahim Yehia

E-mail: sheryyehia@gmail.com

\section{INTRODUCTION}

An occupation is a vocation; a particular business, profession, or trade, in which a person is regularly or usually engaged (1). A primary function of work is to produce and distribute goods and services. It is believed that even work for which there is no economic gain such as child and elderly care, as well as voluntary work, also has its rewards and contributes to personal satisfaction (2).

The World Health Organization (WHO) states that a two-way interaction exists between a person and his/her physical and psychological working environment as it may influence the person's health either positively or negatively, which in turn, influences his/her productivity. If work is associated with health hazards, occupational disease may result in, or can aggravate illness of non-occupational origin (2-4).

Concerns for occupational safety and health were first observed in the Code of Hammurabi that dates back to 2100 BC (5). Greek and Roman physicians, in the era between $400 \mathrm{BC}$ and $300 \mathrm{AD}$, also expressed concern for the health of individuals subjected to metals used during this period (6). In the modern era, Bernadino Ramazzini, an Italian physician, studied diseases related to specific occupations, and collected his observations in a book called "Disease of Workers" (7). With the appearance of the Occupational Safety and Health Act of 1970, the American Congress then created the Occupational Safety and Health Administration Organization (OSHA) to assure safe and healthful working conditions. Currently, there are no specific occupational health and safety administration standards for dentistry, however, dental health care providers are definitely at risk for occupational exposure to a variety of hazardous chemicals and situations $(8,9)$.

These hazards could be biological (e.g. human immunodeficiency virus, hepatitis B or C virus, tuberculosis), chemical (e.g. mercury, acrylic resin materials, composite resins, plaster, latex gloves, disinfectants), physical (e.g. vibration and noise), and musculoskeletal (e.g. strained posture at work, prolonged sitting and/or standing, repetitive movements of shoulder/hand). Other occupational hazards include psychological (e.g. managing uncooperative or difficult patients, workload, time pressure), and radiation hazards (10-16).

In 2013, Mehta et al (17) assessed the various occupational hazards and their prevention among the practicing dentists, in India. A close-ended questionnaire was prepared to record demographic status, types of occupational hazards encountered, and measures used for prevention. The most common occupational hazard reported was injury from "sharps", out of which needle prick injury was the most frequent. Job-related stress, musculoskeletal problems, and allergies from materials used in dental clinics were common hazards. A reasonably high percentage of dentists were immunized against hepatitis-B virus (88.4\%) and were following proper infection control measures as well as adequate hospital waste disposal methods. The study indicated a high prevalence of occupational hazards among the studied group. The authors stressed the need to improve the knowledge of dentists regarding these hazards and the preventive measures to be followed.

Protecting the health care workers (HCWs) contributes to quality patient care and health system strengthening. Therefore, it is required to identify the most prevalent hazards among dentists in order to minimize and prevent their adverse effect on practitioners' health and well-being.

The aim of this study was to assess the prevalence of the different occupational hazards among dentists working in 
the Ministry of Health facilities (MOH) in Alexandria, Egypt.

\section{MATERIALS AND METHODS}

The approval of the Dental Research Ethics Committee at Faculty of Dentistry, Alexandria University was obtained followed by a letter from the faculty explaining the objective of the study and seeking approval of the Alexandria Directorate of Health Affairs in order to gain access to the Healthcare facilities. Furthermore, the permission of the participating dentists was obtained through a detailed explanation of the objectives of the research, in order to gain their trust and confidence as well as their full cooperation.

The current study adopted an analytical, cross-sectional design using a self-administered questionnaire constructed by the researcher and based on literature review $(14,17$ 19). The questionnaire was pilot tested to ensure clarity of the questions and consistency.

Data indicated that the total number of dentists working in the $\mathrm{MOH}$ facilities in Alexandria at the time of conducting the study was 1866 dentists. It was estimated that a sample size of $900(20+21)$ would be representative of the whole dentists' population. A proportional random sample was taken from the various $\mathrm{MOH}$ settings in Alexandria governorate. Data collection took about seven months and in order to ensure the participation of as many dentists as possible, many of the $\mathrm{MOH}$ facilities were approached two to three times throughout the study period. A total of 750 dentists agreed to participate in study with response rate $83.33 \%$. All participants were first introduced to the study objectives in details in order to assure their full cooperation.

The questionnaire was divided into the following two main sections:

Section one:Consisted of questions relating to the personal and demographic characteristics of the study sample, including seven questions about age, gender, qualification, years of practice, average number of actual working hours in the clinic per week, working in a private clinic.

Section two: Involved questions investigating the different occupational hazards to which dentists are subjected in the dental clinic. It consisted of 9 questions that included the biological, musculoskeletal, chemical, radiation and psychological hazards.

\section{Statistical Analysis}

Collected data were revised and coded; then, fed to and analyzed by the Statistical Package for Social Sciences (SPSS 22.0, SPSS, Inc., Chicago, IL, USA.) (22) for Windows. The developed graphs and charts were constructed using Microsoft excel software. All statistical analysis was done using Monte Carlo exact probability test (MCP) (23) in order to display the relation between prevalence of each hazard and the demographic data. The significance level was set at $5 \%(\mathrm{p} \leq 0.05)$.

\section{RESULTS}

Table (1) shows the proportional distribution of the $\mathrm{MOH}$ dentists who participated in the study $(\mathrm{n}=750)$, in relation to the various independent variables,Table (2) demonstrates the prevalence of the different hazards with psychological hazard being the most prevalent where the majority of study sample (85.9\%) viewed dentistry as a stressful profession and more than half (57.6\%) reported feeling overloaded as a symptom of stress (Figure 1). The majority of the study participants (85.6\%) suffered from a sign of Work-related Musculoskeletal Disorders (WMSDs) (table 2), with more than half (56.5\%) suffering from lower back pain (Figure 2).

Table (1): Proportional distribution of the study participants according to the various independent variables.

\begin{tabular}{|c|c|c|c|}
\hline \multicolumn{2}{|c|}{ Personal and Demographic data } & No (750) & $\%$ \\
\hline \multirow{2}{*}{ Age in years } & $20-$ & 405 & $54.0 \%$ \\
& $30-$ & 236 & $31.5 \%$ \\
& $40-$ & 55 & $7.3 \%$ \\
& $50-60$ & 54 & $7.2 \%$ \\
\hline Gender & Male & 154 & $20.5 \%$ \\
& Female & 596 & $79.5 \%$ \\
\hline \multirow{2}{*}{ Qualification } & Bachelor degree & 577 & $76.9 \%$ \\
& Master & 172 & $22.9 \%$ \\
& PHD & 1 & $.1 \%$ \\
\hline Years of practice & $0-10$ & 526 & $70.1 \%$ \\
& $11-20$ & 163 & $21.7 \%$ \\
& $21-30$ & 56 & $7.5 \%$ \\
& $31-40$ & 5 & $.7 \%$ \\
\hline & $2-10$ & 431 & $57.5 \%$ \\
& Yes & 221 & $29.5 \%$ \\
& No & 98 & $13.1 \%$ \\
\hline & & 546 & $46.1 \%$ \\
\hline
\end{tabular}

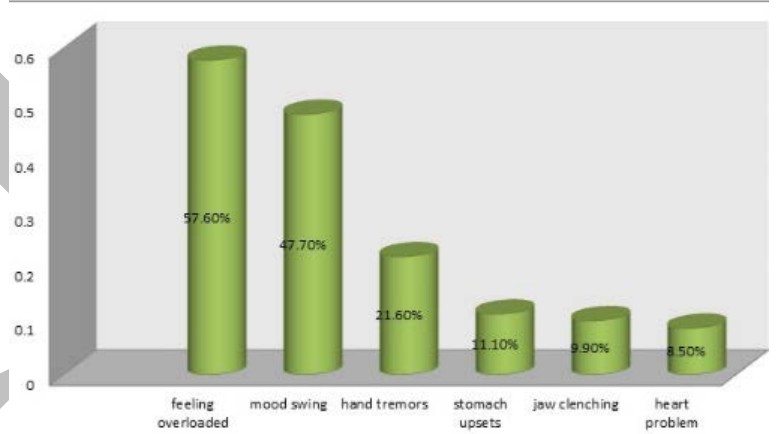

Figure (1): Symptoms of stress among the study participants.

Table (2): Prevalence of the different occupational hazards among the study participants.

\begin{tabular}{|r|c|c|c|c||}
\hline \multirow{2}{*}{ Hazard prevalence } & \multicolumn{2}{|c|}{ No } & \multicolumn{2}{c||}{ \% } \\
\cline { 2 - 5 } & Yes & No & Yes & No \\
\hline Psychological hazards & 644 & 106 & $85.9 \%$ & $14.1 \%$ \\
\hline $\begin{array}{r}\text { Musculoskeletal } \\
\text { disorders }\end{array}$ & 642 & 108 & $85.6 \%$ & $14.4 \%$ \\
\hline Percutaneous injury & 479 & 271 & $63.9 \%$ & $36.1 \%$ \\
\hline Radiological hazards & 384 & 365 & $51.3 \%$ & $48.7 \%$ \\
\hline Eye injuries & 333 & 417 & $44.4 \%$ & $55.6 \%$ \\
\hline Chemical hazards & 320 & 430 & $42.66 \%$ & $57.33 \%$ \\
\hline Hearing impairment & 67 & 682 & $8.8 \%$ & $91.2 \%$ \\
\hline
\end{tabular}




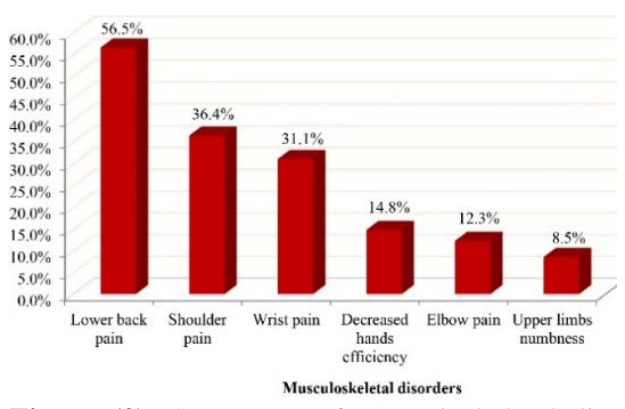

Figure (2): Symptoms of musculoskeletal disorders among the study participants.

The prevalence of percutaneous injuries accounted for $63.9 \%$, whereas $51.3 \%$ reported being subjected to radiological hazards and $42.66 \%$ suffered from chemical hazards such as Latex allergy, Formaldehyde, x-ray processing solutions and mercury. Furthermore, $44.4 \%$ suffered from eye injury and 8.8\% reported hearing impairment.

A significant relationship was observed between all independent variables of the study participants and prevalence of percutaneous injury except for gender as shown in table 3. A significant relation was detected with age and years of practice where more than three-quarters (79.6\%) of those suffering from a percutaneous injury are among the age group of 50-60 years and with years of practice between 3140 years $(80.0 \%)$. Also, the prevalence of injury was higher among specialists (76.5\%). Furthermore, as working hours increased, prevalence of injury increased, where more than two-thirds of those working more than 21 hours per week (73.5\%) were exposed to percutaneous injury and the prevalence was higher among those working in private clinics (76.1\%).

As for chemical hazards, prevalence was significantly higher among females (45.5\%), and those who worked more than 21 hours per week (67.3\%). Prevalence of radiation hazards was significantly higher among the age group of 21-30 years $(58.5 \%)$, males participants $(68.2 \%)$, as well as specialists (57\%). There is a significant increase of eye injury among the age group of 50-60 years (59.3\%) specialists (55.30\%) and those who worked more than 21 hours per week (59.2\%). Prevalence of WMSDs was significantly higher among the age group of 40-49 years (98.2\%). In addition, there was a significant increase of injury among females (93\%), specialists (98.3\%), those who practiced $31-40$ years (100\%) and those who worked more than 21 hours per week (99\%).

Prevalence of hearing impairment was significantly higher among old age (29.62\%), specialists (16.20\%), and those who worked for 31-40 years (40\%) and among those who worked for 2-10 hours per week (94.66\%). Regarding psychological hazards, the only significance observed was related to average working hours, where prevalence was significantly higher among those who worked more than 21 hours per week (92.9\%) (Table 3).

Table (3): Relation between demographic data and prevalence of the different occupational hazards among the study participants.

\begin{tabular}{|c|c|c|c|c|c|c|c|c|}
\hline $\begin{array}{c}\text { Demographi } \\
\text { cs }\end{array}$ & \multicolumn{2}{|c|}{$\begin{array}{l}\text { Percutaneous } \\
\text { injuries }\end{array}$} & $\begin{array}{l}\text { Chemical } \\
\text { hazards }\end{array}$ & $\begin{array}{c}\text { Radiological } \\
\text { hazards }\end{array}$ & $\begin{array}{c}\text { Eye } \\
\text { injuries }\end{array}$ & WMSDs & $\begin{array}{c}\text { Hearing } \\
\text { impairment }\end{array}$ & $\begin{array}{c}\text { Psychological } \\
\text { hazards }\end{array}$ \\
\hline \multirow[t]{4}{*}{ Age } & $21-$ & $59 \%$ & -------- & $58.5 \%$ & $41.2 \%$ & $88.1 \%$ & $5.67 \%$ & ------- \\
\hline & $30-$ & $65.3 \%$ & -------- & $41.1 \%$ & $43.2 \%$ & $94.9 \%$ & $8.89 \%$ & -------- \\
\hline & 40- & $78.2 \%$ & --------- & $52.7 \%$ & $58.2 \%$ & $98.2 \%$ & $10.9 \%$ & ------- \\
\hline & $\begin{array}{c}50- \\
60\end{array}$ & $79.6 \%$ & --- & $40.7 \%$ & $59.3 \%$ & $96.3 \%$ & $29.62 \%$ & ------- \\
\hline MCP & & $0.002 *$ & & $0.001^{*}$ & $0.013^{*}$ & $0.003^{*}$ & $0.000^{*}$ & \\
\hline \multirow[t]{3}{*}{ Gender } & $\begin{array}{c}\text { Mal } \\
\mathrm{e}\end{array}$ & & $33.1 \%$ & $68.2 \%$ & & $86.4 \%$ & --------- & ------- \\
\hline & $\begin{array}{l}\text { Fem } \\
\text { ale }\end{array}$ & -- & 45 & $47 \%$ & --- & $93 \%$ & -------- & -------- \\
\hline & & & $0.006^{*}$ & $0.001^{*}$ & & 0.009* & & \\
\hline \multirow{2}{*}{$\begin{array}{l}\text { Qualificatio } \\
\text { ns }\end{array}$} & GP & $59.9 \%$ & -------- & $49.6 \%$ & $41 \%$ & $89.5 \%$ & $6.47 \%$ & -------- \\
\hline & $\begin{array}{l}\text { Spec } \\
\text { ialist }\end{array}$ & $76.5 \%$ & & $57 \%$ & $55.3 \%$ & $98.3 \%$ & $16.2 \%$ & -------- \\
\hline MCP & & $0.015^{*}$ & & $0.040^{*}$ & $0.015^{*}$ & 0.001* & $0.002 *$ & \\
\hline \multirow{4}{*}{$\begin{array}{l}\text { Years of } \\
\text { practice }\end{array}$} & $0-10$ & $60.8 \%$ & ------ & $54.9 \%$ & -------- & $89.5 \%$ & $6.84 \%$ & -------- \\
\hline & $\begin{array}{l}11- \\
20 \\
\end{array}$ & $68.1 \%$ & & $41.7 \%$ & -------- & $96.3 \%$ & $7.97 \%$ & ------- \\
\hline & $\begin{array}{c}21- \\
30 \\
\end{array}$ & $78.6 \%$ & ------ & $44.6 \%$ & -------- & $96.4 \%$ & $26.78 \%$ & ------- \\
\hline & $\begin{array}{c}31- \\
40 \\
\end{array}$ & $80 \%$ & -------- & $60 \%$ & -------- & $100 \%$ & $40 \%$ & ------ \\
\hline MCP & & $0.027 *$ & & $0.019 *$ & & $0.021^{*}$ & $0.000 *$ & \\
\hline \multirow{3}{*}{$\begin{array}{l}\text { Average } \\
\text { work hours } \\
\text { per week }\end{array}$} & $2-10$ & $60.6 \%$ & $38.3 \%$ & $47.3 \%$ & $44.3 \%$ & $90 \%$ & $94.66 \%$ & $83.8 \%$ \\
\hline & $\begin{array}{c}11- \\
20 \\
\end{array}$ & $66.1 \%$ & $41.2 \%$ & $57 \%$ & $38 \%$ & $91.4 \%$ & $89.59 \%$ & $86.9 \%$ \\
\hline & $21<$ & $73.5 \%$ & $67.3 \%$ & $56.1 \%$ & $59.2 \%$ & $99 \%$ & $79.59 \%$ & $92.9 \%$ \\
\hline MCP & & $0.040^{*}$ & $0.001^{*}$ & $0.038^{*}$ & $0.002 *$ & $0.015^{*}$ & $0.000^{*}$ & $0.050^{*}$ \\
\hline \multirow{2}{*}{$\begin{array}{l}\text { Private } \\
\text { practice }\end{array}$} & Yes & $76.1 \%$ & ------- & $60.4 \%$ & --------- & -------- & ------- & ------- \\
\hline & No & $60.1 \%$ & -------- & $40.8 \%$ & --------- & ------ & --------- & ------- \\
\hline MCP & & $0.048^{*}$ & & $0.001^{*}$ & & & & \\
\hline
\end{tabular}




\section{DISCUSSION}

The importance of Silicone elastomer (SE) in dentistry is evident. They are widely used in fabricating facial prosthesis since 50 years ago.(9) However one of the major problems that patients and maxillofacial prosthodontists commonly faced using these facial appliances is their potential for microbial biofilm formation due to surface texture, hydrophobicity and lack of antimicrobial property of silicone influence, which in turn increase microbial activity of pathogenic skin flora, especially Candida species, and in particular candida albicans. $(4,6,41)$.

Upon accumulation of Candida in the unique microenvironment between facial prosthesis and the skin, the consequences will be a strong immunological reaction develops and dermatitis of the prosthesis-covered skin area occurs. In addition, significantly a disseminated fungal infections for elderly patients.(42) Not only, but probably also, they penetrate into the material, deteriorating color and properties of the prosthetic material,(43-45) which are thought to be the major factors limiting the longevity of facial prostheses.(10)

It has been shown that mechanical cleaning methods are ineffective in complete eradication of microorganisms on facial prosthesis $(13,46)$ particularly with the significant hygiene problems associated with aged hosts.(47) In addition, chemical disinfecting agents are with the sideffects of converting to harmful products $(12,15,48)$. Also, the significantly enhanced resistance of candida biofilm cells to antimicrobial agents(49), making eradication difficult.

Many researchers investigated the modification of the silicone elastomer using variety of surfactant formulations, increasing wettability of silicone surface and therefore reducing microbial adsorption, but unfortunately most of them show deterioration of silicone properties due to water sorption.(50,51) Moreover incorporating conventional antimicrobial drugs such as antifungal / antibiotics into silicone have its own sideffects including drug resistance. $(18,52)$

Nowadays, antimicrobial properties of nano-particles have attracted attention as a new strategy(53). Accordingly, many researches have been devoted to add antimicrobial nanoparticles (NP) to SE materials.

\section{On $\mathrm{TiO}_{2}$ nanoparticles:}

Efforts to add photocatalytic TiO2 NP have attracted much attention. TiO2 is such an inorganic nanoparticles, a white powder, which is a photocatalyst that is activated mainly by UV radiation to produce wide, fast and long-lasting antimicrobial efficacy(297), that can be used as a self cleansing agent.(54) In addition to its unique features including chemical and physical stability, biocompatibility, odour free, availability and low cost; it would be an appropriate substance that can be incorporated into the dental materials.(55) However, the antifungal effect of silicone elastomer containing $\mathrm{TiO} 2$ remains unclear. XRD patterns of the as-purchased Aeroxide TiO2 P25 (15\% Rutile \& 85\% anatase phase) confirmed the respective phases of TiO2. The morphologic characterization of $\mathrm{TiO} 2$ nanoparticles as observed by transmision electron microscopy \& scanning electron microscopic images were $22 \mathrm{~nm}$ and irregular faceted in particle size and shape respectively. Since the $\mathrm{P} 25$ form of $\mathrm{TiO} 2$ showed photocatalytic ability to degrade methylene blue dye and the obtained UV-Vis absorption spectrum range from 320 to
$400 \mathrm{~nm}$ wavelength were consistent with the previous work which was the required form in our work, we continued the use of P25 form in our work.

\section{Sample preparation techniques}

Investigators have suggested incorporation of $\mathrm{TiO} 2$ photocatalyst nanoparticles within material itself and also coating on surface $(21,22)$. The benefit of coating of $\mathrm{TiO} 2$ on the material surface drastically reduces the active micropores sites available that may serve as a reservoir of fungi. At the same time, the incorporation of $\mathrm{TiO} 2$ within the material itself allows constant precence of photocatalyst even if the SE material wears off. On the other hand, incorporation of NP causes these particles to agglomerate and aggregate. Agglomeration of the particles is a big problem that manifests during the preparation of nanocomposites, which in turn impacts diffusion of electron and adversely affect the antimicrobial properties of the polymerized material(25). It is noteworthy that the content of TiO2 NP is of critical importance as it adversely affects degree of dispersion of nano additives in silicone elastomer matrix. Scanning laser microscopic examination of modified silicone elastomer materials to which TiO2 NP added, indicated that all nanosized oxides distribute evenly throughout the silicone specimens, except for the $8 \%$ \& $10 \%(w / w)$ groups, which are partly agglomerated. Our findings suggested that with incorporation of nano-TiO2 at concentrations of $2 \%$ to $10 \%$ by weight into SE proportionally affected the antimicrobial properties of the polymerized material and antifungal rate values are improving with increase in concentration of $\mathrm{TiO} 2$. Also, when the concentration of nano-TiO2 is within the range of $8 \%-10 \%(\mathrm{w} / \mathrm{w})$, the antifungal ability is up to the maximum.

Many efforts have been made to achieve a uniform dispersion state. The most important and widely studied dispersion methods to prohibit association of small particles include calendering, sonication, and mechanical stirring(56). In order to attain a homogenous dispersion of the nanoparticles within silicone elastomer matrix by mechanical mixing using magnetic stirring, the use of a thining agent is necessary, which complicates the manufacturing procedure and may impair the physical and mechanical properties of silicone elastomer(40). Therefore the use of a more powerful mechanical stirring than magnetic ones together with the bulk reduction of the nanoparticles is preferred in the production of polymer matrix nano-composites to handle with such a highly viscous silicone elastomer. It has been also claimed that preparation of $\mathrm{TiO} 2$ nanometer photocatalyst by a hydrothermal method could partly inhibit the agglomeration of TiO2. Thus, the dispersion of nanoparticles was improved(57), optimizing the antimicrobial properties.

In accordance with our results, The research conducted by Lin et al.(25) reported that higher antimicrobial ability has been resulted in nano-TiO2 / rubber composites with bad dispersion state than those nanocomposites without agglomerations. Lin et al.(25) explained that in finer dispersion, the interfacial interactions between $\mathrm{TiO} 2$ and rubber matrix are strong, resulting in impeding effect against diffusion of electron subsequent reactions. While poor dispersion of nano-TiO2 generally means relatively weak interfacial interactions between $\mathrm{TiO} 2$ and rubber matrix, which facilitates diffusion of electrons in the composite. 


\section{Exposure of specimens to light}

The specimens were tested for inhibitory effect at time intervals of 30, 60, 90, and 120 minutes. Exposure of the specimens to UVA light was done during these time intervals. The source of UVA light was blacklight lamp of $15 \mathrm{~W}$ and highest emission at wavelength of $368 \mathrm{~nm}$. Our results also demonstrated that a significant increase in the antifungal rates was observed for candida albicans in silicone elastomer specimens containing $10 \%$ of nanoTiO2, exposed to UVA for $120 \mathrm{~min}$. On the other hand with no nanoparticles in the control group, UVA does not show any significant antimicrobial activity. That means, although UVA could reduce the Candida albicans population, utilizing $\mathrm{TiO} 2$ nanoparticles with UVA would significantly enhance that antifungal activity. This is consistent with the findings of other investigations as $\mathrm{Li}$ et al(24), and considered due to the to the formation of reactive oxygen species with UVA.

The results of this study also show that the antifungal activities of nanoparticles increased with time of irradiation because the last follow-up (after $120 \mathrm{~min}$ ) demonstrated the highest reduction in CFUs of candida. According to Fujishima et al.(58) that a higher intensity of UVA leads to higher photocatalytic activity of nanoparticles and more reactive oxygen species formed. As claimed by Choi et al.(28), the dynamics of the photo-killing process of microorganisms on orthodontic wires coated with TiO2 nanoparticles followed a pseudo-first-order kinetics or two-log inactivation pattern, as a first phase of high antimicrobial activity rate induced, followed by a steady plateau of antimicrobial activity rate at 20-30 min exposure to UVA, after which a reduction of antimicrobial rate phase ensured. That pattern was also reported by Watts et al.(50) while other reports showed two-step dynamics of photokilling process as reported by Sunada et al(29). The latter pattern consisting of a step of a very low-rate antimicrobial activity followed by a higher rate one. However, in the present study, a steady increase in the antifungal rate in the SEs containing $\mathrm{TiO} 2$ nanoparticles was observed up to the last follow-up (after $120 \mathrm{~min}$ ). Thus, a longer follow-up is needed to detect at what time the inhibition trend reaches a plateau.

Based on these theories, it can be claimed that the time necessary to kill the germs was longer in some studies than that reported in others. This can be explained by the differences in the germ resistance. In other words, some microorganisms exhibited more sensitivity to the antimicrobial effects of the nanoparticles than others. Several reports have been proposed for the photo-killing mechanism of TiO2 under UV irradiation. For example, Blake et al(59) reported photocatalysis of microorganisms by $\mathrm{TiO} 2$ was in the order of virus $>$ bacterial cell $>$ bacterial spore and concluded that the order was mainly determined by microorganism type, in particular, cell wall thickness. Another report, Kuhn et al.(60) concluded that the antibacterial effects of $\mathrm{TiO} 2$ is in the order of Escherichia coli > Pseudomonas aeruginosa > Staphylococcus aureus $>$ Enterococcus faecium $>$ Candida albicans and attributed that order mainly to the different thickness and complexity of the cell walls of the microorganism.

However, Haghighi et al(42) found that despite yeast cells of C. albicans are more resistant than bacteria due to their thick cell wall consist of glucan and chitin, $\mathrm{TiO} 2$ nanoparticles had effective antifungal properties against it in comparison to fluconazole as potent antifungal drug(61). It was suggested that direct photocatalytic effect of $\mathrm{TiO} 2$ nanoparticles produce reactive oxygen species (ROS) that induce oxidation of intra cellular Coenzyme A or preoxidation of the membrane phospholipids which decrease respiratory activity and subsequently cause death cell(6264)

The photocatalytic effect of $\mathrm{TiO} 2$ can be enhanced by several ways thus higher microbicidal effect can be achieved. It has been reported that preparation of $\mathrm{TiO} 2$ nanoparticles by a hydrothermal method leads to production of anatase phase which has higher photo catalytic activity than rutile-type(65). However the most photo catalytic activity has been reported when the two phases are mixed with the proportion of $80 \%$ anatase plus $20 \%$ rutile as in Aeroxide TiO2 P25 (Sigma aldrich Inc., USA) utilized in the present study.(66)

Not to be lost in this discussion is the effect of $\mathrm{TiO} 2$ modification on the mechanical properties of the final product. It is well known from Han et al(67) study mentioned previously in literature review that $\mathrm{TiO} 2$ nanoparticles at concentrations of $2.0 \%$ and $2.5 \%$ improved the overall mechanical properties of the silicone maxillofacial elastomer. Increasing concentrations of nanoparticles means higher photocatalytic and microbicidal activity but that does not necessarily means higher mechanical properties. As can be seen in sodagar et al(68) study. As in the results of our study, when the concentration of nano-TiO2 is within the range of $4 \%-6 \%(w / w)$, the tear strength is up to the maximum. As $\mathrm{TiO} 2 \mathrm{NP}$ exceeded a particular percentage of $6 \mathrm{wt} \%$ in elastomer matrix, an opposite trend was observed and the value of tear strength decreased. In order to enhance photocatalytic activity of the $\mathrm{TiO} 2$ without increasing the concentration of nanoparticles, an appropriate source of UVA irradiation should be applied.

Taking the advantages of UVA as the patients should be instructed to keep their facial prosthetic appliances containing nano-TiO2 for about $3 \mathrm{~min}$ to $5 \mathrm{~min}$ in outdoors under sun exposure between 9.30 am to 11 am and 2 pm to $3.30 \mathrm{pm}$ when incidental UVB and infrared rays responsible for heat are less(69) or for about 2 h under UVA lamps with an intensity of $1 \mathrm{~mW} / \mathrm{cm} 2$ during the night. Thus, if these instructions are followed, there will be lesser microbial load in the facial prosthesis, hoping to preserve the facial prostheses from microbial deteriorations, increasing its longevity and decreasing the number of hospital visits have been made previously to remake the damaged prosthesis, lowering costs on society, and also protecting the patient from any dangerous biofilm induced local and systemic disorders and subsequently a better quality of life ensured

A limitation of this study is that just one brand of $\mathrm{TiO} 2$ nanoparticles was applied. As previously reported by Lin et al(25) adding $\mathrm{TiO} 2$ nanoparticles from two different manufacturer to rubber, the results were conflicting no similar trends in antimicrobial values of the two types of $\mathrm{TiO} 2$ were observed as the concentration of NP were increased. However, the result of the current study, concur with Wang et al.'s(26), although the applied TiO2 were not identical in these two investigations. Moreover, defeated microorganisms were not similar, staphylococcus aureus in Wang(26) and Candida albicans in ours. 
Also we could not achieve our goal in testing the specimens under visible light, in the dark and for longer duration of exposure to UVA to confirm the photokilling activity of TiO2 in the nanocomposite. Moreover, in light of the importance of the effect of aging on the properties of silicone elastomer material containing nanoparticles, the lack of retesting the specimens after accelerated aging to evaluate the effect of nanoparticles after some time-interval, can be a limitation in this study. To address this issue, further studies should be considered.

\section{CONCLUSION}

Proper nutrition plays a vital role in the well-being of a person. Fish oil rich in omega-3 fatty acids have a proven role in resolving inflammation. Not only the lack of serious side effects and the positive health benefits of fish oil, but also its remarkable therapeutic effect proven from this study in case of rheumatoid arthritis induced rats, it should be considered as an acceptable approach for most arthritic individuals.

\section{CONFLICT OF INTEREST}

The authors declare that they have no conflicts of interest.

\section{REFERENCES}

1. Bevaart L, Vervoordeldonk MJ, Tak PP. Evaluation of Therapeutic Targets in Animal Models of Arthritis. How Does It Relate to Rheumatoid Arthritis? Arthritis Rheum. 2010; 62:2192-205.

2. Grassi W, De Angelis R, Lamanna G, Cervini C. The clinical rheumatoid arthritis. Eur J Radiol. 1998; 27:18-24.

3. Block SR. Guidelines for the management of rheumatoid arthritis. Arthritis Rheum. 2002; 46:328-46.

4. Müller-Ladner U, Pap T, Gay RE, Neidhart M, Gay S. Mechanisms of disease: the molecular and cellular basis of joint destruction in rheumatoid arthritis. Nat Clin Pract Rheumatol. 2005; 1:102-10.

5. Haynes DR, Crotti TN, Loric M, Bain GI, Atkins GJ, Findlay DM. Osteoprotegrin and receptor activator of nuclear factor kappa B ligand (RANKL) regulate osteoclast formation by cells in the human rheumatoid arthritis joint. Rheumatology. 2001:40; 623-30.

6. Corrado A, Neve A, Maruotti N, Cantatore FP. Bone effects of biologic drugs in rheumatoid arthritis. Clin Dev Immunol. 2013; 2013:1-7.

7. Fit N, Chirilă F, Răpuntean S, Nadăş G, Preoteasa L, Cumpănaşu F. Haematological and biochemical investigations in rats with rheumatoid arthritis induced by Freund Complete Adjuvant and treated with bee venom. Veterinary Medicine. 2011; 68; 151-8.

8. Kässer UR, Gleissner C, Dehne F, Michel A, Willershausen-Zönnchen B, Bolten WW. Risk for periodontal disease in patients with longstanding rheumatoid arthritis. Arthritis Rheum. 1997; 40:2248-51.

9. Mercado F, Marshall R. Inter-relationships between rheumatoid arthritis and periodontal disease. Journal of Clinical Periodontology. 2003; 30:761-72.

10. Pischon N, Pischon T. Association among rheumatoid arthritis, oral hygiene, and periodontitis. Journal of Periodontology. 2008; 79:979-86.

11. Maroon JC, Bost JB. Nature's safest, most effective antiinflammatory: fish oil: the natural anti-inflammatory. Library of congress: E-Publishing; 2006:37.
12. Turchini GM, Wing-Keong NG, Tocher DR. Fish oil replacement and alternative lipid sources in aquaculture feeds. Tyalor and Francis group: E-Publishing; 2010:12-13.

13. Leeb BF, Sautner J, Andel I, Rintelen B. Intravenous application of omega-3 fatty acids in patients with active rheumatoid arthritis. Lipids. 2006;41:29-34

14. Simopoulos AP. The importance of the omega-6/omega-3 fatty acid ratio in cardiovascular disease and other chronic diseases. Exp Biol Med. 2008; 233:674-88.

15. Firestein GS, Budd RC, Gabriel SE, Mcinnes IB, O'dell JR. Kelley's textbook of rheumatology. $9^{\text {th }}$ ed. Elsevier Inc.; 2013:1049-52.

16. Kremer JM. N-3 fatty acids supplements in rheumatoid arthritis. Am J Clin Nutr. 2000; 71:349-51.

17. Kesavalu L, Vasudevan B, Raghu B, Browning E, Dawson D, Novak JM. Omega-3 fatty acid effect on alveolar bone loss in rats. J Dent Res. 2006:85:648-52.

18. Sun D, Krishnan A, Zaman K, Lawrence R, Bhattacharya A, Fernandes G. Dietary n-3 fatty acids decrease osteoclastogenesis and loss of bone mass in ovariectomized mice. J Bone Miner Res. 2003; 18:1206-16.

19. Hasturk H, Kantarci A, Ohira T, Arita M, Ebrahimi N, Chiang N. RvE1 protects from local inflammation and osteoclast-mediated bone destruction in periodontitis. FASEB J. 2006; 20:401-3.

20. Banji D, Pinnapureddy J, Otilia JF, Banji A, Kumar R. Evaluation of the concomitant use of methotrexate and curcumin on Freund's complete adjuvant-induced arthritis and hematological indices in rats. Narsi Reddy Indian J Pharmacol. 2011; 43: 546-50.

21. Vardar S1, Buduneli E, Türkoğlu O, Berdeli AH, Baylas H, Başkesen A, et al. Therapeutic versus prophylactic plus therapeutic administration of omega-3 fatty acid on endotoxin-induced periodontitis in rats. 2004; 75:1640-6.

22. Suresh P1, KavithaChN, Babu SM, Reddy VP, Latha AK. Effect of ethanol extract of Trigonella foenumgraecum (Fenugreek) seeds on Freund's adjuvant-induced arthritis in albino rats. 2012; 35:1314-21.

23. Bashkar SN. Orban oral histology and embryology. Torteno: Mosby; 1990:365-473.

24. Dunn CA, Jin Q, Taba M, Renny T. Franceschi, R. BMD gene delivery for alveolar bone engineering at dental implants defects. Molecular therapy. 2005; 11; 295-9.

25. Kirkpatrick LA, Feeney BC. A simple guide to IBM SPSS statistics for version 20.0. Student ed. Belmont, Calif.: Wadsworth, Cengage Learning; 2013.

26. Fit N, Chirila F, Rapuntean S, Nadas G. Haematological and Biochemical Investigations in Rats with Rheumatoid Arthritis Induced by Freund Complete Adjuvant and Treated with Bee Venom. Veterinary Medicine. 2011; 68:151-8.

27. Aizer J, Reed G, Onofrei A, Harisson MJ. Predictors of bone density testing in patients with rheumatoid arthritis. Rheumatol Int. 2009; 29:897-905.

28. Park JC, Su C, Jung IH, Choi SH. Mechanism of alveolar bone loss in a collagen-induced arthritis model in mice. 2011; 38:122-30.

29. Bernstein CN, Blanchard JF, Leslie W, Wajda A. The incidence of fracture among patients with inflammatory bowel disease: a population-based cohort study. Annals of Internal Medicine. 2000; 133:95-100.

30. Bultink IEM, Lems WF, Kostense PJ, Dijkmans BAC, Voskuyl AE. Prevalence of and risk factors for low bone mineral density and vertebral fractures in patients with 
systemic lupus erythematosus. Arthritis and Rheumatism. 2005; 52: 2044-50.

31. Sambrook PN. The skeleton in rheumatoid arthritis: common mechanisms for bone erosion and osteoporosis. J Rheumatol. 2000; 27:2541-2.

32. Bahadori B, Uitz E, Thonhofer R. Omega-3-fatty acid infusions as adjuvant therapy in rheumatoid arthritis. J Parenter Enteral Nutr. 2010; 34:151-5.

33. Ruggiero C, Lattanzio F, Lauretani F, Gasperini B, AndresLacueva C, Cherubini A. Omega-3 polyunsaturated fatty acids and immune-mediated diseases: inflammatory bowel disease and rheumatoid arthritis. 2009; 15:4135-48.

34. Alam SQ, Kokkinos PP, Alam BS. Fatty acid composition and arachidonic acid concentrations in alveolar bone of rats fed diets with different lipids. Calcif Tissue Int. 1993; 3552.

35. Serhan CN, Gotlinger K, Hong S, Arita M. Resolvins, docosatrienes, and neuroprotectins, novel omega-3-derived mediators, and their aspirin-triggered endogenous epimers: an overview of their protective roles in catabasis. Prostaglandins Other Lipid Mediat. 2004; 73:155-72.
36. Herrera BS, Ohira T, Gao L, Omori K, Yang R. An endogenous regulator of inflammation, resolvin $\mathrm{E} 1$, modulates osteoclast differentiation and bone resorption. $\mathrm{Br}$ J Pharmacol. 2008; 155:1214-23.

37. Poulsen RC, Gotlinger KH, Serhan CN, Kruger MC. Identification of inflammatory and proresolving lipid mediators in bone marrow and their lipidomic profiles with ovariectomy and omega-3 intake. Am J Hematol. 2008; 83:437-45.

38. James MJ, Gibson RA, Cleland LG. Dietary polyunsaturated fatty acids and inflammatory mediator production. Am J Clin Nutr. 2000; 71:343-8.

39. Poulsen RC, Moughan PJ, Kruger MC. Longchainpolyunsaturated fatty acids and the regulation of bone metabolism. Exp Biol Med. 2007; 232:1275-88.

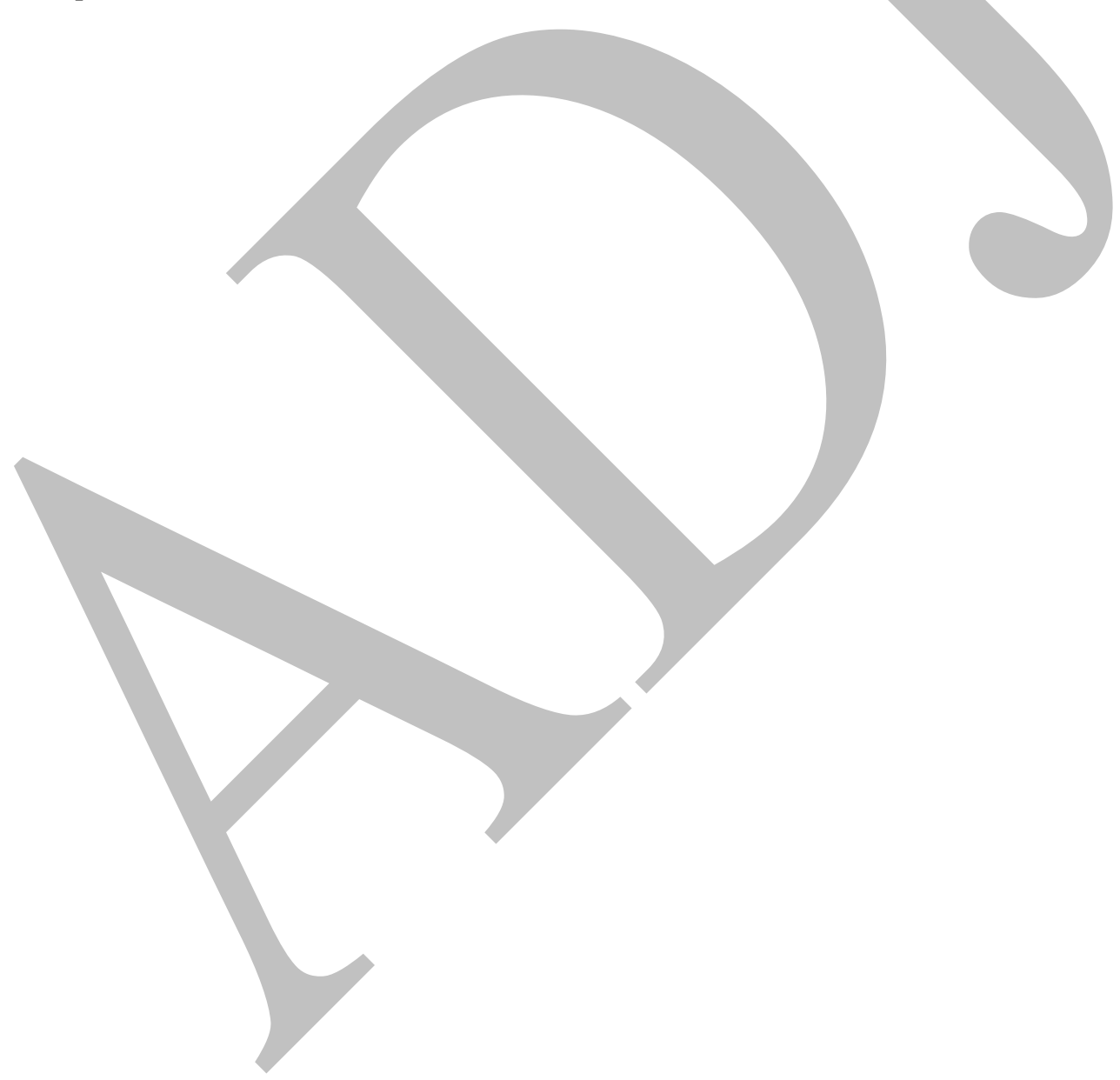

